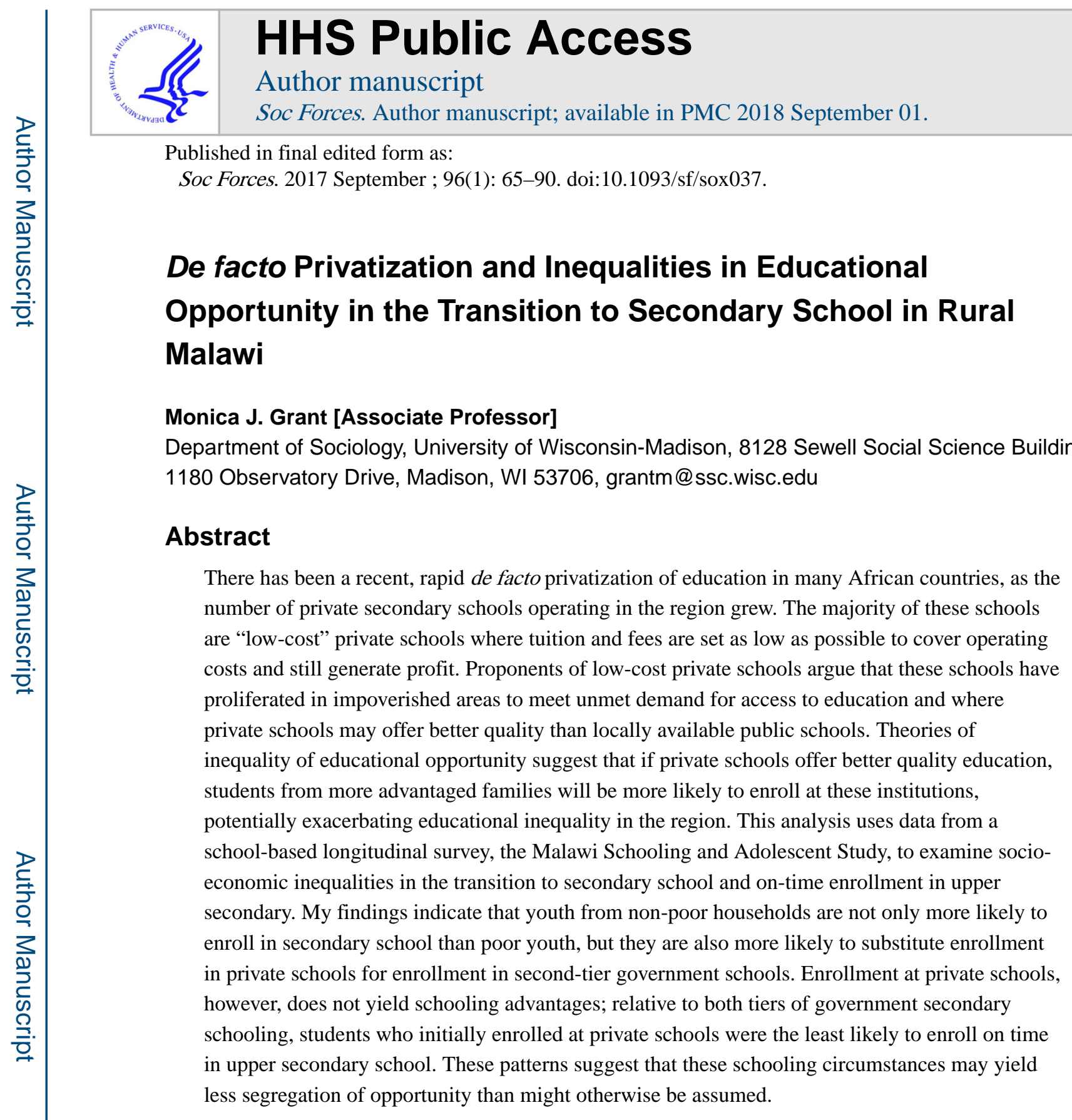

\title{
Introduction
}

The expansion of schooling has been promoted as a key development initiative for decades. Over the past thirty years, gender gaps in educational attainment in many African countries have narrowed substantially (Grant and Behrman 2010; Jones and Ramchod 2014); socioeconomic inequalities, however, persist. Although national policies to remove school fees and encourage universal primary education have increased school participation rates, poverty remains an important obstacle to educational attainment (Birdsall, Levine, and Ibrahim 2005). Sociological research on the inequality of educational opportunity in developed countries has emphasized how schooling expansions that reduce socioeconomic 
inequality at one level of schooling may magnify socioeconomic inequalities at higher levels of schooling (Raftery and Hout 1993; Mare 1981). Extensions and critiques of this research have posited that as participation at a given level of schooling becomes universal, advantaged families will seek qualitative advantages for their children (Lucas 2001). Although some research has focused on Latin America or East Asia, these theories have not been widely examined within low income countries, particularly sub-Saharan Africa.

In the years following the World Declaration of Education for All at the Jomtien conference in 1990, many countries in sub-Saharan Africa implemented policies that eliminated primary school fees as a means of reducing the financial barriers to school enrollment among the poor. Despite gains in primary school enrollments, socioeconomic inequalities in schooling attainment persist, such that children from the richest 20 percent of households in subSaharan Africa are six times more likely to reach the ninth grade than children from the poorest 40 percent of households (Lewin 2009). In particular, socioeconomic inequalities widen as students transition from free primary schools to secondary schools that require school fees. Although free primary education (FPE) policies have brought more children into school and increased the number of students with basic skills (Taylor and Spaull 2015), the financial barriers to entering and completing secondary school may limit the long term economic development gains of these policies as few young adults in sub-Saharan Africa without secondary schooling are able to access wage employment (Filmer and Fox 2014).

Secondary school enrollments increased over the past fifteen years, despite limited access to government secondary schools. This growth is partly due to the expansion of the private school sector (World Bank 2010). It is unclear, however, how the newly opened private schools are affecting inequality in access to secondary school. Private schools may be providing a new pathway through which advantaged youth are able to gain secondary school admission or they may be targeting disadvantaged youth and underserved areas that lack a local secondary school. In this paper, I examine socioeconomic inequalities in the transition to secondary school in Malawi, a country that typifies the combination of weak state provision of quality education, ability tracking into secondary school, and rapid privatization of secondary education that is common throughout low income countries in sub-Saharan Africa.

In 1994, Malawi eliminated primary school fees. As a consequence, school enrollment rates increased and school entry has become virtually universal (World Bank 2010). Although poverty still prevents a large proportion of children from completing primary school (Kadzamira and Rose 2003), socioeconomic inequalities are particularly pronounced at the transition to secondary school, where tuition and other school fees are a greater financial barrier to enrollment. I use a longitudinal, school-based survey of youth from rural Malawi to investigate how family socioeconomic status affects the transition to secondary school and whether this association is mediated by the student's academic performance in primary school. Furthermore, I examine the consequences of attending a private or government school for timely progress through secondary school, operationalized here as enrolling on time in the first year of upper secondary school two years after beginning secondary. 


\section{Inequality of Educational Opportunity}

Most sociological theories describing the relationship between educational expansion and socioeconomic inequality are rooted in the experiences of developed countries. Early theoretical iterations focused on the modernization process, hypothesizing from the experience of industrialized countries that as a country develops, the overall educational attainment of the population will increase in response to a demand for skilled labor. This expansion, in turn, will lead to a decline in the effect of family background on educational attainment (Treiman 1970). Subsequent research, however, found that socioeconomic inequalities persisted over time in many industrialized countries. The theory of maximally maintained inequality emerged as a way to explain persisting inequalities in the context of expanding education systems. As educational attainment increases and participation at one level of schooling, such as primary school, becomes nearly universal across socioeconomic groups, inequalities will increase at the next level of schooling that remains relatively rare (Raftery and Hout 1993; Mare 1981). Maximally maintained inequality, therefore, refers to quantitative differences in educational attainment by socioeconomic background. In contrast, the theory of effectively maintained inequality (EMI) argues that socioeconomic differences in educational attainment can still exist in contexts of where a schooling transition is saturated. The differences, however, are ones of quality rather than quantity as students and their families translate socioeconomic advantages into better schooling options within a level of education (Lucas 2001). In his work focusing on the American educational system, Lucas considers secondary school track placement as an exemplar of effectively maintained inequality. In the Malawian context, however, I argue that the relevant horizontal gradient is the type of secondary school children attend.

To the extent that these theories have been applied to low- and middle-income countries, most studies focused on patterns of schooling expansion in East Asia or Latin America. An early study from the Philippines, for example, found that the association between father's education and years of schooling completed declined across cohorts over the $20^{\text {th }}$ century, but inequalities persisted at key education transitions (Smith and Cheung 1986). Other studies have highlighted how education policies that preferentially target disadvantaged populations can reduce inequality within that group, even as inequalities persist or increase for other groups or in the population overall (Pong 1993; Wu 2010). Similarly, Post (1994) found that when a free and universal lower secondary education policy was implemented in Hong Kong - primarily in the form of public subsidies to private schools-not only did the odds of students transitioning from primary to secondary school increase, but socioeconomic inequality in the transition substantially declined. Post, however, did not explore whether qualitative differences in lower secondary school enrollment emerged as enrollment became universal.

Recent studies from Latin America, in contrast, found evidence for increasing inequality within the context of education expansion. Although the effect of socioeconomic background on primary school completion and the transition into secondary school declined across cohorts in a range of countries over the past twenty years, inequalities increased in private school enrollment as more advantaged families sought qualitatively better schooling environments for their children (Marteleto et al. 2012). In Chile, students who enrolled in 
private secondary schools had higher probabilities of completing secondary school than students enrolled at public schools following the implementation of a national voucher program, and these benefits were net of additional advantages derived from higher socioeconomic status (Torche 2005). A separate study of the voucher program in Chile and a similar program in Brazil found that disadvantaged families were less likely to use vouchers to choose a higher achieving school, contributing to the processes of widening inequality (Alves et al. 2015). The advantages of private school enrollment were based, in part, on selection effects as private schools attracted higher status students and were able to use their own admission standards to admit higher performing students in contrast to public schools which were required to accept all students. Private schools also may have influenced schooling attainment through peer effects created via student sorting across schools and by having different organizational features than public schools, such as greater autonomy of management decisions and accountability to local school officials (Torche 2005). A voucher system in Colombia randomly assigned private school vouchers to 125,000 low-income high school students and, similarly, increased secondary school completion rates (Angrist, Bettinger, and Kremer 2006). In contrast to the voucher program in Chile, the Colombian program has been praised for reducing educational inequalities by targeting vouchers at students from low income neighborhoods.

\section{The Expansion of Private Schools in sub-Saharan Africa}

The expansion of private schools in sub-Saharan Africa, however, has not relied upon student vouchers or government subsidies to privately operated schools, as was the case in many countries in Latin America and Asia (Patrinos, Osorio, and Guáqueta 2009). Public resources for secondary education in sub-Saharan Africa are often limited. Most African countries only have enough places in government secondary schools to accommodate a fraction of the students who are eligible to attend, leaving insufficient resources to subsidize privately operated schools.[1] These pressures have increased since the mid-1990s when free primary education policies were implemented and the number of students completing primary school began to increase. This period of schooling expansion capitalized on political demands to democratize educational opportunities but took place largely in the absence of economic growth (Riddell 2004; Oketch and Rolleston 2007); mass primary education was often pursued at the expense of school quality, while access to high quality secondary and post-secondary education remained highly constrained (Buchmann and Hannum 2001; Fuller 1991). As demand for secondary schooling grew, many countries lacked the resources to expand secondary school enrollments. Consequently, there was a rapid de facto privatization of education in many African countries, as the number of private secondary schools operating in the region grew with little or no regulation (Tooley and Dixon 2006; Rose 2005; Verspoor 2008; Rolleston and Adefeso-Olateju 2014). Although some private schools are operated or funded by NGOs or religious missions, the majority are run by local entrepreneurs and are "low-cost" or "low-fee" schools where tuition and fees are set as low as possible to cover operating costs and still generate profit (Lewin 2007).

[1] In Malawi, a small fraction of private schools are classified as "grant-aided" and receive public subsidies. These mostly consist of church and mission schools, where a majority of seats are set aside for students admitted through the government's allocation process. 
Proponents of low-cost private schools argue that these schools have proliferated in impoverished urban and peri-urban areas to meet unmet demand for access to education and where private schools may offer better quality than locally available public schools (Tooley and Dixon 2006; Oketch et al. 2010). Teachers at private schools are directly accountable to locally-based proprietors and to parents, yielding lower levels of teacher absenteeism relative to government schools (Tooley and Dixon 2006; Das et al. 2007). Furthermore, poor parents perceive less social distance between themselves and teachers at private schools relative to teachers at government schools; private school teachers typically have lower qualifications and are more likely to come from the local community than government school teachers, making them more accessible to parents who have less school-related cultural capital (Rolleston and Adefeso-Olateju 2014). Finally, cross-national studies have found that students at private schools have higher standardized test scores than students at government schools (Tooley and Dixon 2006; Jimenez, Lockheed, and Paqueo 1991; Wößmann 2007), contributing to the perception that private schools are able to offer better quality at lower costs. International policymakers have argued that the availability of lowcost private schools will create competition between schools in the public and private sectors, encouraging private schools to keep costs low and forcing government schools to improve their quality in order to retain students and resources (Patrinos et al. 2009).

In contrast, critics of low-cost private schools argue that these schools exacerbate socioeconomic inequalities in educational attainment. Even at the minimum possible fee, these schools remain too expensive for all but the wealthiest quartile of households in subSaharan Africa (Lewin 2007; Verspoor 2008). The initial expansion of private schools in Tanzania, for example, expanded access for advantaged young people and resulted in greater inequality of access to secondary school (Lassibille, Tan, and Sumra 2000), and in Cote d'Ivoire private school students come from families with substantially higher incomes than children at public schools (Sakellariou and Patrinos 2009). Furthermore, a recent study in Kenya found that the abolition of primary school fees led to the transfer of wealthier students to private schools (Nishimura and Yamano 2013).

The de facto privatization of secondary schooling in sub-Saharan Africa, driven by the expansion of low-cost private schools, offers a sharp contrast to secondary school expansion in Latin America and East Asia where relatively well regulated public-private partnerships prevailed. Given that the transition to secondary school is unsaturated in most countries in sub-Saharan Africa and access to public secondary schools is often rationed by performance on national examinations (Lewin 2007), low-cost private schools may create opportunities for lower performing but socioeconomically advantaged students to enroll in secondary school. Alternately, low-cost private schools may pull advantaged students away from government schools that are perceived to be of lower quality, potentially segregating the public and private schooling sectors by student socioeconomic status. If private secondary schools yield better academic outcomes than government schools, as observed in other world regions, then the sorting of students by socioeconomic status into different school sectors will reproduce socioeconomic inequalities. 


\section{Secondary Schooling in Malawi}

Malawi is consistently described as one of the poorest countries in the world; its gross national income per capita recently ranked 180 out of 187 countries at US\$350 (UNDP 2013). Despite its low economic performance, the primary school gross enrollment ratio for Malawi is higher than the average for sub-Saharan Africa. The enrollment ratios are on par for Malawi's peer countries in the Southern African Development Community (SADC), even though many of the SADC countries rank among the most developed in sub-Saharan Africa. Participation in secondary school, however, is much lower. The secondary school gross enrollment ratio in Malawi is only a third as high as the levels estimated for the other SADC countries (World Bank 2010).

Admission to public secondary school in Malawi is regulated by performance on the Primary School Leaving Certificate examination (PSLCE), taken at the end of the eighth grade. Test scores on the PSLCE are used to place students into government secondary schools, where places are only available for approximately 40 percent of the students who successfully pass the PSLCE in a given year. According to test score, students are sorted into national boarding schools, district boarding schools, and district day schools, which are collectively referred to as conventional secondary schools (CSS). A small subset of high scoring students are also allocated places at church or mission schools that are subsidized by the government; the majority of students at these schools are assigned based on PSLCE scores, but as many as 40 percent of places are reserved for students who perform well on each school's own entrance examination. Students who do not receive a place at a CSS or church/mission school may be offered admission to a community day secondary school (CDSS). As shown in Figure 1, enrollment at the community day schools increased rapidly after the implementation of the FPE policy in 1994. Enrollments in the CDSS peaked in 1999, briefly declined, and have steadily increased since the early 2000s. Prior to 1998, when the CDSS were officially established, many of these schools operated as distance education centers, although new schools were also built. Despite serving the majority of youth enrolled in government secondary schools, the CDSS persist as a second tier of schooling: school quality, education resources, and teacher qualifications are much lower than in conventional secondary schools (World Bank 2004). Finally, a small number of students attend open or night secondary schools which are typically operated at CDSS facilities outside of typical school hours.

Private secondary schools operate as an alternative to the government school system. Most of these schools are for-profit institutions operated by individual entrepreneurs or family businesses. Although elite secondary schools with international curricula exist in urban areas, the majority of private schools have few admission standards other than the ability to pay the tuition which is usually between $\$ 12$ and $\$ 88$ per term. In contrast, students at the CDSS and CSS pay $\$ 7.50$ and $\$ 50$, respectively, per term (Chimombo et al. 2014). Despite the higher tuition expenses, many private schools outside large urban centers have fewer resources than government schools. The teaching staff at most private schools is poorly qualified and many schools have insufficient learning materials and physical infrastructure. Nonetheless, the average pass rate on the Malawi School Certification of Education 
(MSCE), taken at the end of secondary school, is comparable in private schools and the CSS and substantially higher than the average pass rates for the CDSS (World Bank 2010).

In a recent qualitative study, parents reported using a school's exam pass rate as a proxy for school quality; the higher pass rate at private schools relative to the CDSS, therefore, motivates some parents to enroll their children at private schools even when they are eligible to enroll at a government school (Chimombo et al. 2014). This study also found high enrollment volatility among private school students. Students frequently switch between private schools or back and forth between private schools and the CDSS after each year's exam results are released, although switching may be limited by the local availability of alternatives and a student's enrollment eligibility. School switching is also common after the second year of secondary school, when students take the Junior Certificate of Education (JCE) exam, which must be passed in order to proceed to the last two years of secondary school, or upper secondary. Students who do not pass the JCE often repeat the final year of junior secondary in order to re-take the exam, sometimes switching to a different school at that time.

Although the government formally increased the number of secondary schools through the expansion of the CDSS, the number of private schools in Malawi increased with minimal regulation (Rose 2005). The number of students enrolled in private secondary schools began to increase in 2002 (Figure 1). By 2008, 31 percent of all secondary school students attended private schools. In 2009, however, the government formed a national inspectorate which shut down private schools that were identified as substandard, defined as having insufficient purpose-built physical infrastructure and less than 50 percent qualified teachers. Enrollment in private schools plummeted in the years immediately after these closures, but in 2012 still accounted for almost 25 percent of all secondary school students.[2]

In this paper, I use longitudinal data from Malawi to investigate how family socioeconomic status is associated with the transition into secondary school, whether this association varies by student performance on the primary school leaving exam, and whether initial enrollment patterns are subsequently associated with timely progress through secondary school. I expect students from the wealthiest quartile of households to be more likely than other students to transition into secondary and to enroll in private secondary schools than students from less advantaged households. If socioeconomically advantaged students are using enrollment in private schools to access qualitatively better schooling environments, then I would expect students enrolled at private schools to be more likely than students at government schools to enroll on time in upper secondary, and that school switching will mitigate differences in ontime progress by initial school type. Together, these analyses provide new insights into how de facto privatization influences education stratification in a low income country and point towards a more complex understanding of how socioeconomic advantages shape educational opportunity.

\footnotetext{
[2] Official estimates of private school enrollment in Malawi undercount the actual enrollment numbers, given that some private schools are unregistered or the proprietors did not respond to the annual government survey that collects enrollment information. The non-response of private schools worsened after the 2009 policy that closed sub-standard private schools; less than 75 percent of registered private schools responded to the 2012 survey. Official estimates are not adjusted to control for non-response and response rates are not always reported with the enrollment statistics.
} 


\section{Data and Methods}

The Malawi Schooling and Adolescent Study (MSAS) is a longitudinal, school-based survey that first sampled a cohort of adolescents who were aged 14-16 years at the beginning of the school year in 2007. The original sample consisted of 1,764 students who were randomly chosen from the enrollment rosters of 59 government primary schools in two adjacent rural districts in southern Malawi, Balaka and Machinga. Prior to 1998, these two districts were part of the same district and share a common administrative history, but Balaka is more densely populated than Machinga (National Statistical Office 2008). Balaka district has the highest prevalence of private schools in Malawi following only behind the four largest urban areas, whereas Machinga ranks in the bottom quarter of districts for private school availability (Chimombo et al 2014). Sampled schools were randomly selected from a list of all government primary schools in the two districts, with the probability of a particular school being included proportional to its enrollment in 2006. At each school approximately 30 students stratified by gender and age who were enrolled in grades 4-8 were interviewed. An additional 886 14-17 year olds who were no longer enrolled in school (but who lived in the communities from which the primary schools drew their students) were identified by key informants.[3] Respondents were re-interviewed annually from 2007 until 2013.[4] At each survey round, approximately 94 percent of respondents who were enrolled in school at the previous survey round were successfully re-interviewed and respondents were reinterviewed, on average, in at least four subsequent survey rounds.

The original sample was limited to 14-16 year olds who were enrolled in primary schoolor who had recently left school-in 2007. These criteria exclude 14-16 year olds who had already completed primary school and progressed to secondary school. According to the 2004 Malawi Demographic and Health survey, 76 percent of 14-16 year old students were still enrolled in school, 92 percent at the primary level (author calculations). It is likely that the small fraction of 14-16 year olds who were already enrolled in secondary school were more advantaged than those still enrolled in primary; in order to maintain on-time progress through primary school, these youth would have had to have both entered primary school at the correct age and avoided grade repetition, conditions that require tremendous social and economic support from families.

\section{Dependent Variables}

The first section of the analysis examines the transition to secondary school. This variable groups respondents who completed primary school into four categories. The first category identifies respondents who never attended secondary school and the remaining three categories identify the type of secondary school in which a respondent first enrolled: Firsttier (Conventional Secondary Schools and Church/Mission Schools) and Second-tier Government (Community Day Secondary Schools and Night/Open Schools), and Private.

\footnotetext{
[3] Of the original out-of-school sample, 77 respondents had completed standard 8 but were not enrolled in secondary; these respondents are included in the analysis, with characteristics at Round 1 proxying characteristics at the time of primary school completion. An additional 25 respondents eventually returned to school and completed primary by 2012; these respondents are also included in the analysis.

${ }^{[4]}$ Data were not collected in 2012 due to budget constraints.
} 
These three categories of school enrollment are the main independent variable in the second section of the analysis.

The second section of the analysis focuses on whether secondary school type is associated with qualitative differences in academic outcomes. In particular, I examine whether students enrolled on time in the first year of upper secondary school. Students are unable to enroll in upper secondary school unless they have passed the junior secondary certificate of education (JCE), taken near the end of the second year of secondary school. Although MSAS respondents were asked to report their JCE performance, a large proportion of respondents reported that they didn't know or were still waiting to learn their test results. Enrolling in the first year of upper secondary school, however, is a clear indicator that the respondent passed the exam, and enrolling on time also indicates that the respondent did not repeat any grades of secondary school or have any enrollment disruptions.[5]

\section{Independent Variables}

All analyses include a set of socio-demographic control variables that include the respondent's sex, ethnic group (Yao, Chewa, Lomwe, and Other ethnic groups), district, parents' marital status, socioeconomic status, age at primary school completion, and whether the respondent repeated standard 8, the final year of primary school. District is a binary variable for the district from which the respondent was originally sampled. Parents' marital status was defined as whether the respondent's mother and father were still married to each other, a parent had died, or the parents were divorced, all measured at the time of primary completion. Socioeconomic status is measured two ways. First, an index of household asset ownership (Filmer and Pritchett 1999) was calculated, based on the year in which the respondent completed primary school. A principal components analysis was run for 14 household assets: mattress, sofa, table, chair, lamp, television, radio, cell phone, mosquito net, motorcycle, car, tin roof, electricity, and boat. The first principal component estimated for the entire sample at round 1 data was used to calculate an asset index for all subsequent survey rounds, such that values on the asset index are standardized relative to the average round 1 asset ownership. Preliminary analyses indicated that there were significant differences in the transition to secondary school between the highest asset quartile and the three lower quartiles, but no significant differences between the three lower quartiles. Therefore, the asset quartiles were converted into a binary variable, such that respondents in the highest wealth quartile were coded as the non-poor and all remaining respondents were coded as poor. By standardizing asset ownership, this variable is flexible to how household wealth changes over time; for example, 15 percent of respondents who were classified as poor at round 1 lived in households that were non-poor by the time the respondent completed primary school. This operationalization also allows me to test Lewin's assertion that only students from the wealthiest quartile of families would be able to afford the fees at low-cost private schools in sub-Saharan Africa. The second measure of socioeconomic status was an indicator of whether a respondent's mother ever attended primary school. A third

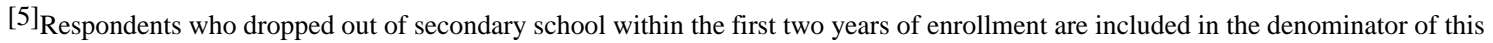
analysis. 
category identified cases where the mother's educational attainment was missing or unknown.

In addition to these socio-demographic controls, I also include a binary variable to indicate whether a respondent completed primary school in 2009 or later. Respondents who completed primary school in 2009 or later faced more limited secondary school options following the government's closure of substandard private schools that year, and are likely to have different enrollment outcomes than students who completed primary school before 2009.

These analyses also include the respondent's self-reported performance on the primary school leaving certificate examination (PSLCE). The exam covered five subjectsChichewa, English, mathematics, primary science, and social studies. Although the precise exam scores calculated by the Malawi National Examination Board are used to assign students to a first- or second-tier government school, exam takers only learn the letter grade (A-F) that corresponds with their exam score in each subject. I converted these grades into a grade point average that is used as a proxy for the respondent's test score. Students are allowed to repeat the final year of primary school in order to improve their performance on the PSLCE; therefore, I use the highest overall test score reported by a respondent in this analysis. When a respondent reported that they did not know their score on one subject, their test score was calculated as the average of the reported scores.

Finally, the analysis of respondents' on time enrollment in upper secondary includes an indicator of whether the respondent reported switching out of their initial secondary school within the first two years of attending that school. School switching was determined by comparing the name of the school attended in one round to the name of the school attended in the subsequent round. All respondents who switched from one school to another at any point during the first two years of secondary school are coded as having ever switched schools. Respondents who switched schools between lower and upper secondary are included in the definition of having ever switched schools.

\section{Analytic Methods}

1317 respondents completed primary by 2012, but 72 respondents did not report the name of their secondary school[6] and 176 respondents did not report a PSLCE score,[7] yielding a final analytic sample of 1069 students. The first section of the analysis uses multinomial logit regression to examine the transition to secondary school. The assumption of the independence of irrelevant alternatives posits that the choice of membership in one category of the dependent variable is not related to the choice of membership in another category. The current model conceptualizes not enrolling in secondary school as one of many enrollment choices facing students and their families. An alternate approach might see this as a two-

\footnotetext{
[6]Preliminary models that included unknown school type as a fifth category in the multinomial logit regression found that females, students who completed primary at older ages, and students with higher PSLCE scores had significantly higher marginal probabilities of being in this group.

[7] Two-thirds of respondents with missing PSLCE test scores did not enroll in secondary school. Fifteen percent enrolled in a CDSS, 10 percent in a private school, 4 percent at a CSS, and 2 percent attended either an open/night school or a church/mission school. An alternate specification used multiple imputation to recover these cases for analysis; the regression estimates based on the imputation were virtually identical to those estimated without the imputation.
} 
stage process, where families first decide whether to enroll a child in secondary school and then choose the type of secondary school. A post-estimation Hausman test on the preliminary analyses found no significant differences in the estimation of the coefficients when never enrolling in secondary was excluded from the dependent variable (Chi2 $=4.54$, $\mathrm{p}=1.00$ ), suggesting that the first approach is valid.

The second section of the analysis uses logit regression to examine whether the respondents who entered secondary school enrolled on time in upper secondary. This regression is limited to respondents who began secondary school and were re-interviewed two survey rounds later, yielding an analytic sample of 729.[8] Although both analytic samples are selected on prior schooling transitions-completing primary school and entering secondary school, respectively - these models do not control for selection. Given that poor students are less likely to complete primary school, the regressions are likely to underestimate the effect of household poverty status on secondary school outcomes. All regressions are adjusted for sampling weights and the clustering of respondents by sample schools to account for the complex survey design.

\section{Results \\ Descriptive Results}

Table 1 shows that 19 percent of students who completed primary school never enrolled in secondary school. Less than 16 percent of students initially enrolled at a first-tier secondary school, the top tier of government secondary schools and church/mission schools with the highest test score requirements. Thirty-nine percent of students enrolled at the second tier of government secondary schools. Finally, 26 percent of all students who completed primary school initially enrolled at a private school. Of students who enrolled in secondary school, differences by initial school type in the percent of students who progressed on time to upper secondary school are evident. Sixty-six percent of students who enrolled at a first-tier school and 53 percent of students enrolled at a second-tier government school began upper secondary school two years later. In contrast, only 42 percent of students who initially enrolled at a private school had enrolled on time in upper secondary.

The characteristics of the analytic sample, adjusted for sampling weights and clustering by original sample school, are provided in Table 1 by socioeconomic status. Thirty-eight percent of primary school completers came from households defined as "non-poor," reflecting both increased household wealth between round 1 and primary school completion and lower levels of primary school completion among the poor (Schafer 2006; Kadzamira and Rose 2003). The transition to secondary school was significantly different for poor and non-poor students. Poor students were significantly more likely to not enter secondary school or to enroll at a second-tier government school, whereas non-poor students were more likely to enroll at either a private or first-tier school. There were no statistically

\footnotetext{
${ }^{[8]}$ An additional 101 respondents entered secondary school but were not reinterviewed two years later; the majority of these cases were respondents who entered secondary school within the last three years of the MSAS and were either not reinterviewed in the final survey round or were censored when data collection ended in 2013.
} 
significant differences by socioeconomic status in the percentage who enrolled on time in upper secondary school two years later.

Although the initial sample was evenly divided between boys and girls, only 36 percent of the analytic sample that completed primary school was comprised of female students. The Yao were the largest ethnic group in the sample, with 37 percent of respondents, followed by the Lomwe (27 percent) and the Chewa (21 percent). The final 15 percent of the first analytic sample combined all other ethnic groups. The average respondent was 16.5 years old in at the time of primary school completion and reported an average score of 1.94 on the primary school leaving certificate exam (PSLCE). Sixty-two percent of respondents completed primary school before 2009, when the transition into secondary school was unaffected by the national policy to close substandard private secondary schools.

Thirty-seven percent of the first analytic sample had mothers who did not attend school, 58 percent had mothers who had at least some primary schooling, and the remaining five percent did not know their mother's educational history. Finally, almost half of respondents had parents who were still married to each other. Thirteen percent had been orphaned and the parents of the remaining 37 percent had divorced. Non-poor respondents were significantly more likely to have mothers who attended primary school and parents who were still married to each other.

Finally, 36 percent of students who began secondary school switched schools within the first two years. Switching was more common among students from non-poor households. More than half of students who initially enrolled in private secondary schools switched schools, relative to 27 percent of first-tier and 25 percent of second-tier government school students. The most common pathways of school switching were from private schools to second-tier government schools or to other private schools, while students from all school types were least likely to switch into a first-tier school.

\section{Transition to Secondary School}

Table 2 shows the average marginal effects estimated from the multinomial regression for the transition to secondary school. The first column presents the average marginal effects in relation to not enrolling in secondary school. Subsequent columns show the average marginal effects for initially enrolling at a second-tier government school, first-tier school, or private school.

Students whose families were in the highest asset quartile, the "non-poor," had significantly lower probabilities of not enrolling in secondary school or of initially enrolling at a secondtier school relative to students from poor families, but had five percent higher probabilities of enrolling at a first-tier school. Students whose mothers attended school had significantly lower probabilities of never enrolling in secondary school and significantly higher probabilities of enrolling at a first- or second-tier government school relative to students whose mothers never attended school. The pattern of marginal effects for initially enrolling in private school, however, indicate that these two measures of socioeconomic status do not always operate in the same way. Students from non-poor families had 10 percent higher probabilities of enrolling at a private school relative to students from poor families. Students 
with educated mothers, however, had 7 percent lower probabilities of enrolling at a private school, indicating that the association between socioeconomic status and initial secondary school type varies according to how socioeconomic status is measured.

Each additional grade-point improvement on the primary school leaving certificate exam (PSLCE) decreased the probability of never enrolling by five percent. A grade-point on the PSLCE was also associated with a 10 percent higher probability of initially enrolling at a first-tier school and a 7 percent lower probability of initially enrolling at a private school. In order to examine whether private secondary schools primarily attracted socioeconomically advantaged but lower performing students who would not be eligible to attend a government secondary school, I estimated a second regression model that estimated the interaction between household poverty status and performance on the PSLCE. The average marginal effects of poverty status at select PSLCE scores are presented in Table 3, [9] but the key results from this model are presented visually: Figures 2a-2d present the predicted probability of never enrolling in secondary, enrolling at a private school, enrolling at a second-tier government school, and enrolling at a first-tier school, respectively, predicted from the model that estimates the interaction between household poverty status and PSLCE performance.

Figure 2a shows that the predicted probability of never enrolling among students from poor households is not associated with the PSLCE test score and remains steady around 25 percent for all poor students who completed primary school before 2009. In contrast, among the non-poor, the predicted probability of never enrolling in secondary school declines sharply as performance on the PSLCE improves. If private schools enabled more advantaged but lower performing students to enter secondary school, I would not have expected to see this negative association. Poor students are significantly more likely than non-poor students to not enroll in secondary at all PSLCE scores above 2.0. Although the predicted probability of being out of school at very low test scores is higher for non-poor students, only 14 percent of non-poor students had test scores below 1.5 as compared to almost 24 percent of poor students. Figure $2 \mathrm{a}$ also reflects the statistically significant difference in the predicted probabilities of never enrolling in secondary school by year of primary school completion.

Among poor students who completed primary school before 2009, the predicted probability of enrolling at a private secondary school declines as performance on the PSLCE increases (Figure $2 b$ ). This pattern suggests that poor students who receive test scores that qualify them to enroll in government secondary schools are less likely to substitute enrollment in private schools for enrollment in government schools. Given that tuition at low-cost private schools is substantially higher than tuition at second-tier government schools, the enrollment decisions of poor families are likely driven by financial constraints. In contrast, for students from non-poor households whose PSLCE test scores were less than 2.5, the predicted probability of enrolling at a private school increases as test scores increase. Above 2.5, the predicted probability declines slightly as test scores increase, although non-poor students have significantly higher probabilities of attending private schools than poor students for all

${ }^{[9]}$ An additional model (not shown) included the interaction between mother's education and PSLCE test score. None of these interaction terms were statistically significant and this model is not included with the paper. 
PSLCE scores above 2.0. Students with high test scores are potentially eligible to enroll at the relatively high quality first-tier schools, suggesting that this is a desirable alternative for some non-poor families. The figure also shows the substantially lower predicted probabilities of enrolling at a private school for students who completed primary school in 2009 or later, reflecting the more limited opportunities to attend private schools after the government closed schools considered to be sub-standard.

Figures $2 \mathrm{c}$ and $2 \mathrm{~d}$ show that the predicted probability of enrolling at a second-tier government school follows an inverse U-shape with relation to PSLCE test scores, whereas the predicted probability of enrolling at a first-tier school increases monotonically with PSLCE performance. These distributions correspond to the higher PSLCE threshold for enrollment at the first-tier schools relative to the second-tier. It is also important to note that in Figure 2c, the poor had higher predicted probabilities of enrolling at the second-tier than the non-poor at all levels of performance on the PSLCE (although this difference was only statistically significant at PSLCE=2.0), whereas non-poor students had higher probabilities of enrolling in a private school for all test scores greater than 1.5. These figures provide further evidence that non-poor students are for the most part substituting enrollment in private schools for enrollment in second-tier government secondary schools at all but the lowest levels of test performance. In contrast, the predicted probability that poor students will enroll at a private school is negatively associated with test performance, suggesting that poor families whose children qualify for enrollment at government schools-which typically cost less than private schools-are not making the same substitution. This pattern also suggests, contrary to expectation, that some low performing poor students are predicted to enroll at private schools when they otherwise would not be eligible to enroll in secondary school.

Figures $2 \mathrm{c}$ and $2 \mathrm{~d}$ also show that the predicted probability of enrolling at either a first- or second-tier government school increased substantially over time for both poor and non-poor students. Together with Figures $2 a$ and $2 b$, these figures suggest that private school enrollment largely served as a substitute for enrolling at government schools and that the closure of sub-standard private schools did not increase the proportion of students unable to transition to secondary school. Further evidence for this conclusion is observed in Figure 1, which shows an increase in the number of students enrolled in the community day secondary schools beginning in 2010 .

In addition to these findings, several other covariates are significantly associated with the transition to secondary school. The results in Table 2 indicate that girls have significantly higher marginal probabilities of never enrolling in secondary school, but there are no significant gender differences in the type of secondary school in which students initially enroll. Contrary to expectations, students who repeated the final year of primary school had significantly higher marginal probabilities of never enrolling in secondary school and significantly lower marginal probabilities of initially enrolling at a private school, but was not associated with enrollment in either tier of government schools. Older ages at primary school completion, parental death, and parental divorce were associated with higher marginal probabilities of never enrolling in secondary school. Students with at least one dead parent had lower marginal probabilities of initially enrolling at a private school, 
whereas students whose parents were divorced had lower marginal probabilities of initially enrolling at a second-tier government school.

\section{Progress through Secondary School}

Table 4 presents average marginal effects for the regression results for on-time enrollment in upper secondary, conditional on ever enrolling in secondary. Model 1 shows that both nonpoor status and having an educated mother were associated with higher probabilities of ontime progress, although neither of these associations achieved statistical significance. There was also no significant association between PSLCE test score and on-time progress. Students who completed primary school in 2009 or later, however, had significantly higher marginal probabilities of on-time enrollment than students who completed primary school before 2009.

Contrary to my hypothesis, initial enrollment in private secondary schools was not associated with better secondary school outcomes. Model 2 shows that students who initially enrolled at a second-tier or private school had probabilities of progressing on time to upper secondary that were 11 and 21 percentage points lower, respectively, than those of students who initially enrolled in first-tier schools. When a measure for whether a student switched schools within the first two years of secondary school was added to Model 3, the relationship between school type and on time progress strengthened. The third model also indicates school switching had no significant effect on the probability of enrolling on time in upper secondary.

An additional model examined the interaction between initial school type and school switching; the predicted probabilities of on time enrollment in upper secondary school, based on this model, are presented in Figure 3. For both tiers of government schools, there were no statistically significant differences in the predicted probabilities for students who switched and did not switch. In contrast, the figure shows that school switching yielded statistically significant benefit to students initially enrolled at a private school.

Approximately 24 percent of private school students who did not switch schools were predicted to enroll on time in upper secondary, compared to 53 percent of private school students who switched schools. Almost two-thirds of students who initially enrolled at a private school but switched during the first two years of school reported switching to a government secondary school, potentially reflecting both the limited availability of private schools after 2009, lower school fees at government schools, and potential recognition by families that more students at government schools were successfully progressing through secondary. This option, however, was only available to students who initially scored high enough on the PSLCE to qualify for government school enrollment or who had exceptional performance on the JCE exam taken at the end of lower secondary. Additional analyses (results not shown) indicate that students at private secondary schools have significantly higher probabilities of dropping out of school than students who initially enrolled in either tier of government schools, but school switching reduces the probability of dropout.

Finally, girls had significantly lower marginal probabilities than boys of enrolling on time in upper secondary. There is no evidence of significant interactions between gender and school type (results not shown), indicating that the magnitude of gender gaps in progress through 
secondary school do not vary across first-tier, second-tier, and private schools. Older students also had significantly lower marginal probabilities of enrolling on time in upper secondary.

\section{Discussion}

The de facto privatization of secondary schooling in sub-Saharan Africa presents a new context for considering the dynamics of schooling inequalities. Most new private secondary schools built in the region over the past twenty years have been low-cost private schools, established in part due to rising demand for secondary education in the years following the implementation of free primary education policies. While international policymakers have touted the potential of low-cost schools to reduce inequalities of access to education, other scholars have cautioned that these schools may still have fees that are too expensive for the majority of African families (Lewin 2007). In this study, I used longitudinal data from Malawi to examine how family socioeconomic status is associated with the transition to secondary school and subsequent on time progress to upper secondary. Collected twenty years after the onset of schooling expansion in Malawi, these data provide important insights into the current state of inequality.

At first glance, these data are consistent with other examples of effectively maintained inequality, as better resourced families seek quantitative and qualitative schooling advantages for their children. Youth from non-poor households are not only more likely to enroll in secondary school than poor youth, but they are also more likely to substitute enrollment in private schools for enrollment in second-tier government schools, consistent with evidence from other African countries (Lassibille et al. 2000; Sakellariou and Patrinos 2009; Nishimura and Yamano 2013). Enrollment at private schools, however, does not actually yield schooling advantages; relative to both sectors of government secondary schooling, students who initially enrolled at private schools were the least likely to enroll on time in upper secondary school. The data indicate that students who attend private schools are significantly more likely than students at first- and second-tier government schools to drop out of secondary school and less likely to enroll on time in upper secondary: less than one-quarter of the students who initially enrolled at a private secondary school and did not switch to a different school within the first two years entered upper secondary on time, compared to 66 percent of students initially enrolled at first-tier government secondary schools.

Given that private schools are associated with worse secondary school outcomes than either tier of government schools, this raises the question of why relatively wealthier families are making "bad" decisions about their children's schooling. First, parents may be making secondary school enrollment decisions in response to incomplete information about the quality of private schools. Chimombo and colleagues (2014) note that families often use the average pass rates on the exams taken at the end of the second and fourth years of secondary school as indicators of a school's quality; pass rates at private schools are often comparable to those at first-tier government schools, contributing to the perception that private schools serve as a higher quality alternative to second-tier government schools (Tooley and Dixon 2006; Jimenez et al. 1991; Wößmann 2007). My findings, however, suggest that pass rates 
provide a biased picture and do not reflect the selectivity of which students remain in school long enough to take the exams. A more informative statistic would reflect the percent of each entering cohort that successfully passed the junior secondary exam or indicate a school's dropout or transfer rate.

Second, it is important to remember that families may choose secondary schools for reasons other than school quality. Private schools are independently operated and their locations are not dictated by the local district education commissioner. Private schools in rural areas, therefore, may be in closer proximity than the nearest government school, enabling students to have a shorter and less expensive commute from home. Qualitative studies of private schools in low-income settings have also found that parents perceive the quality of parentteacher interactions to be better at private schools (Rolleston and Adefeso-Olateju 2014). These closer relationships-and potentially closer geographic proximity-not only potentially enable parents to have better communication with teachers about school-related issues but also facilitate the supervision of students and teachers. I also found that students whose mothers ever attended school were more likely to attend any government school than private school, controlling for household wealth, indicating that not all household advantages lead families to choose private schools. Issues of social distance and the need to supervise teachers may be less relevant for students whose mother attended school; parents' schooling experiences may be sufficient to provide basic cultural capital about how government schools work, leading to greater comfort interacting with—or deferring toteachers at these schools.

Although the focus of this paper is socioeconomic inequality in the transition to and pathways through secondary school, it is helpful to contextualize these findings relative to other dimensions of inequality, such as gender. As gender gaps in grade attainment have narrowed across sub-Saharan Africa, some studies have noted that socioeconomic inequalities are now larger than gender inequalities in many countries; nonetheless, female disadvantages persist in the transition to secondary school in many countries (Grant and Behrman 2010; Jones and Ramchand 2016; Eloundou-Enyegue, Makki, and Giroux 2009). In the MSAS data, the gender gap in secondary school ever enrollment is twice as large as the socioeconomic gap, and the marginal probability that girls will enroll on-time in upper secondary is more than 30 percentage points lower than that of boys. That adolescent girls face greater barriers to continued school enrollment is not surprising. What is interesting, however, is that households are not privileging the enrollment of sons over daughters in private school, in contrast to evidence that households with more resources are substituting enrollment in private schools for enrollment in second-tier government schools.

There are several limitations to the data. First, PSLCE test scores are self-reported by respondents as letter grades rather than the precise scores measured by the national examination board. This imprecision and inaccuracy creates some inconsistencies, such as respondents who report both low test scores and enrollment at a conventional secondary school, despite the improbability of this outcome. However, the overall distribution of PSLCE test scores by school type and the pattern of predicted probabilities of enrollment by test score observed in Figures $2 \mathrm{c}$ and $2 \mathrm{~d}$ is close to what would be expected for the two tiers of government secondary school. A related issue is that all school enrollments are self- 
reported and not verified against school records. Third, household wealth is measured by an asset index. Although this measure is commonly used to study education in low income countries (Filmer and Pritchett 1999), it does not provide information about income shocks or volatility that may be more relevant for paying school fees. The absence of an association between poverty status and on-time enrollment in upper secondary may reflect this limitation. Unobserved financial assistance from extended family members may also help poor households cover the cost of school fees and buffer against any underlying socioeconomic differential. Finally, the sample was not drawn from urban areas and, therefore, excludes both the most advantaged Malawian youth and the elite private schools with international curriculums that serve them. Approximately 85 percent of the population of Malawi, however, is estimated to live in rural areas (Government of Malawi 2008); this study, therefore, provides information about the schooling contexts in which the majority of youth live. If these analyses had been conducted with nationally representative data, I would expect to find larger socioeconomic differentials than were identified here.

The expansion of secondary education in sub-Saharan Africa has been facilitated by a diversification of school types via the growth of private schools and expansion of a less selective tier of government schools. Although these data from Malawi show that there was partial socioeconomic segregation by school type, almost a quarter of students from poor households initially enrolled at private schools. The majority of secondary school enrollment by the poor was at second-tier government schools, but these data demonstrate that low-cost private schools may not be as financially inaccessible as Lewin (2007) feared. Given that students at private schools had worse secondary attainment outcomes than students in either tier of government school, these data suggest greater need to understand the consequences of the pathways that students in sub-Saharan Africa take through secondary school. To the extent that schooling expansion has been encouraged as a mechanism for economic development, it is important to understand whether private schools and second-tier government schools deliver employment opportunities similar to the more selective tier of government schools. The consequences of these pathways are likely to vary across countries, depending on the extent of state regulation and the capacity of governments to maintain educational quality.

\section{Acknowledgments}

The paper benefited from comments from conference participants, as well as feedback from and conversations with Joseph Chimombo, Amita Chudgar, Eric Grodsky, Esme Kadzamira, Nancy Kendall, and Valerie Lee. I appreciate conversations about this project with members of the MSAS research team, especially Barbara Mensch, Erica SolerHampejsek, and Stephanie Psaki. I am grateful to data assistance from Martin Masanche and Maclean Kaluwa at the Ministry of Education, Science \& Technology in Malawi, and my research assistant, Jinho Kim. The MSAS was collected with support from the Eunice Kennedy Shriver National Institute for Child Health and Human Development (R01 HD062155) and the Spencer Foundation (200700065). The analysis was funded by a National Academy of Education/Spencer Foundation Fellowship. Additional support was provided by a core grant from the Eunice Kennedy Shriver National Institute for Child Health and Human Development (P2C HD047873) to the Center for Demography and Ecology at the University of Wisconsin-Madison.

\section{Biography}

Monica J. Grant is an Associate Professor of Sociology at the University of WisconsinMadison. Her research interests include the demographic consequences of schooling 
expansion, gender differences in the transition to adulthood, and family change in sub-

Saharan Africa. She has recently published articles in Demography, Population and

Development Review, and Studies in Family Planning.

\section{References}

Alves, Fatima, et al. Winners and losers of school choice: Evidence from Rio de Janeiro, Brazil and Santiago, Chile. International Journal of Educational Development. 2015; 41:25-34.

Angrist, Joshua, Bettinger, Eric, Kremer, Michael. Long-Term Educational Consequences of Secondary School Vouchers : Evidence from Administrative Records in Colombia. American Economic Review. 2006; 96:847-872.

Birdsall, Nancy, Levine, Ruth, Ibrahim, Amina. Towards Universal Primary Education: investments, incentives, and institutions. European Journal of Education. 2005; 40:337-349.

Buchmann, Claudia, Hannum, Emily. Education and Stratification in Developing Countries: A Review of Theories and Research. Annual Review of Sociology. 2001; 27:77-102.

Chimombo, Joseph, Meke, Elizabeth, Zeitlyn, Benjamin, Lewin, Keith M. Increasing Access to Secondary School: Education in Malawi: Does Private Schooling Deliver on its Promises?. Sussex: 2014.

Das, Jishnu, Dercon, Stefan, Habyarimana, James, Krishnan, Pramila. Teacher Shocks and Student Learning: Evidence from Zambia. Journal of Human Resources. 2007; 42:820-862.

Eloundou-Enyegue, Parfait, Makki, Fouad, Giroux, Sarah C. Sex versus SES: A Declining Significance of Gender for Schooling in sub-Saharan Africa. International Perspectives on Education and Society. 2009; 10:1-37.

Filmer, Deon, Fox, Louise. Youth Employment in Sub-Saharan Africa. Washington, DC: The World Bank; 2014.

Filmer, Deon, Pritchett, Lant. The Effect of Household Wealth on Educational Attainment: Evidence from 35 Countries. Population and Development Review. 1999; 25:85-120.

Fuller, Bruce. Growing-Up Modern: The Western State Builds Third-World School. New York, NY: Routledge; 1991.

Grant, Monica J., Behrman, Jere R. Gender Gaps in Educational Attainment in Less Developed Countries. Population and Development Review. 2010; 36:1-22.

Jimenez, Emmanuel, Lockheed, Marlaine E., Paqueo, Vicente. The Relative Efficiency of Private and Public Schools in Developing Countries. The World Bank Research Observer. 1991; 6:205-218.

Jones, Gavin W., Ramchand, Divya S. Closing the Gender and Socio-Economic Gaps in Educational Attainment: a Need To Refocus. Journal of International Development. 2016; 28:953-973.

Kadzamira, Esme, Rose, Pauline. Can free primary education meet the needs of the poor? Evidence from Malawi. International Journal of Educational Development. 2003; 23:501-516.

Lassibille, Gerard, Tan, Jee-Peng, Sumra, Suleman. Expansion of Private Secondary Education: Lessons from Recent Experience in Tanzania. Comparative Education Review. 2000; 44:1-28.

Lewin, Keith M. The Limits to Growth of Non-Government Private Schooling in Sub-Saharan Africa. Brighton; Sussex, UK: 2007.

Lewin, Keith M. Access to education in sub-Saharan Africa: patterns, problems and possibilities. Comparative Education. 2009; 45:151-174.

Lucas, Samuel R. Effectively Maintained Inequality: Education Transitions, Track Mobility, and Social Background Effects. American Journal of Sociology. 2001; 106:1642-1690.

Mare, Robert D. Change and Stability in Educational Stratification. American Sociological Review. 1981; 46:72-87.

Marteleto, Letícia, Gelber, Denisse, Hubert, Celia, Salinas, Viviana. Educational Inequalities among Latin American Adolescents: Continuities and Changes over the 1980s, 1990s and 2000s.

Research in social stratification and mobility. 2012; 30:352-375. [PubMed: 22962512]

National Statistical Office. Population and Housing Census Main Report. Zomba; Malawi: 2008. 
Nishimura, Mikiko, Takashi, Yamano. Emerging Private Education in Africa: Determinants of School Choice in Rural Kenya. World Development. 2013; 43:266-275.

Oketch, Moses, Mutisya, Maurice, Ngware, Moses, Ezeh, Alex C. Why are there proportionately more poor pupils enrolled in non-state schools in urban Kenya in spite of FPE policy? International Journal of Educational Development. 2010; 30:23-32.

Oketch, Moses, Rolleston, Caine. Policies on Free Primary and Secondary Education in East Africa: Retrospect and Prospect. Review of Research in Education. 2007; 31:131-158.

Patrinos, Harry, Felipe, Anthony, Osorio, Barrera, Guáqueta, Juliana. The Role and Impact of PublicPrivate Partnerships in Education. Washington, DC: World Bank; 2009.

Pong, Suet-ling. Preferential Policies and Secondary School Attainment in Peninsular Malaysia. Sociology of Education. 1993; 66:245-261.

Post, David. Educational Stratification, School Expansion, and Public Policy in Hong Kong. Sociology of Education. 1994; 67:121-138.

Raftery, Adrian E., Hout, Michael. Maximally Maintained Inequality: Expansion, Reform, and Opportunity in Irish Education, 1921-75. Sociology of Education. 1993; 66:41-62.

Riddell, Rubin, Abby. The introduction of free primary education in sub-Saharan Africa. UNESCO. 2004:1-24.

Rolleston, Caine, Adefeso-Olateju, Modupe. De facto Privatisation of Basic Education in Africa: A Market Response to Government Failure? A Comparative Study of the Cases of Ghana and Nigeria. In: MacPherson, IanRobertson, Susan, Walford, Geoffrey, editors. Education, Privatisation and Social Justice. Oxford, UK: Symposium Books; 2014. p. 25-44.

Rose, Pauline. Privatisation and decentralisation of schooling in Malawi: default or design? Compare: A Journal of Comparative and International Education. 2005; 35:153-165.

Sakellariou, Chris, Anthony Patrinos, Harry. The equity impact of public finance of private education provision in Côte d'Ivoire. International Journal of Educational Development. 2009; 29:350-356.

Schafer, Mark J. Household Change and Rural School Enrollment in Malawi and Kenya. The Sociological Quarterly. 2006; 47:665-691.

Smith, Herbert L., Cheung, Paul P L. Trends in the Effects of Family Background on Educational Attainment in the Philippines. American Journal of Sociology. 1986; 91:1387-1408.

Taylor, Stephen, Spaull, Nicholas. Measuring access to learning over a period of increased access to schooling: The case of Southern and Eastern Africa since 2000. International Journal of Educational Development. 2015; 41:47-59.

Tooley, James, Dixon, Pauline. 'De facto' privatisation of education and the poor: implications of a study from sub- Saharan Africa and India. Compare: A Journal of Comparative and International Education. 2006; 36:443-462.

Torche F. Privatization Reform and Inequality of Educational Opportunity: The Case of Chile. Sociology of Education. 2005; 78:316-343.

Verspoor, Adriaan M. At the Crossroads: Choices for Secondary Education in Sub-Saharan Africa. Washington, DC: The World Bank; 2008.

World Bank. Cost, Financing and School Effectiveness of Education in Malawi: A future of limited choices and endless opportunities. Washington, DC: 2004.

World Bank. The Education System in Malawi. Washington, DC: 2010.

Wößmann, Ludger. International Evidence on School Competition, Autonomy, and Accountability: A Review. Peabody Journal of Education. 2007; 82:473-497.

$\mathrm{Wu}$, Xiaogang. Economic Transition, School Expansion, and Educational Inequality in China, 19902000. Research in Social Stratification and Mobility. 2010; 28:91-108. 


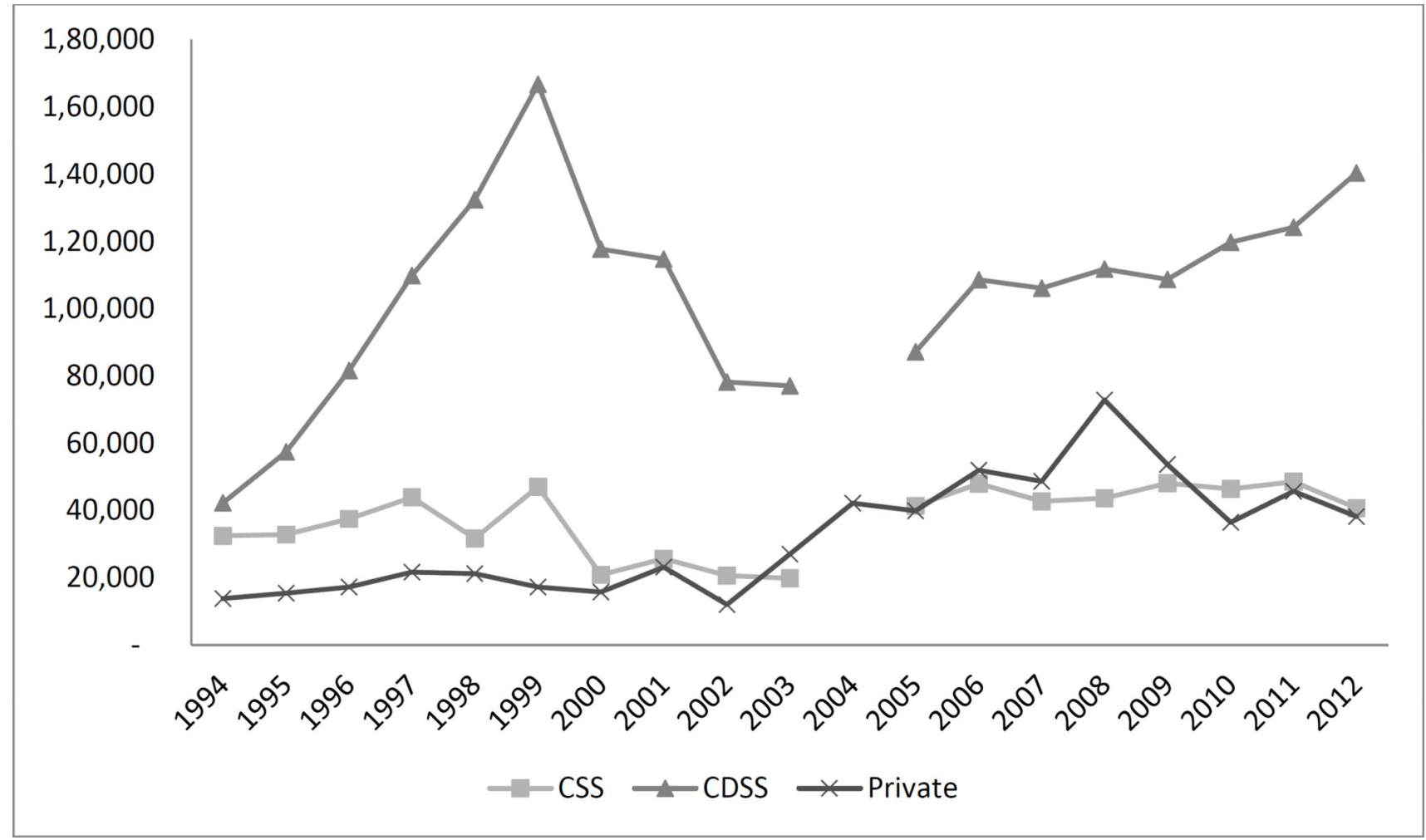

Figure 1.

Secondary school enrollments, by secondary school type, Malawi 1994-2012

Source: Government of Malawi, Education Management Information Systems 


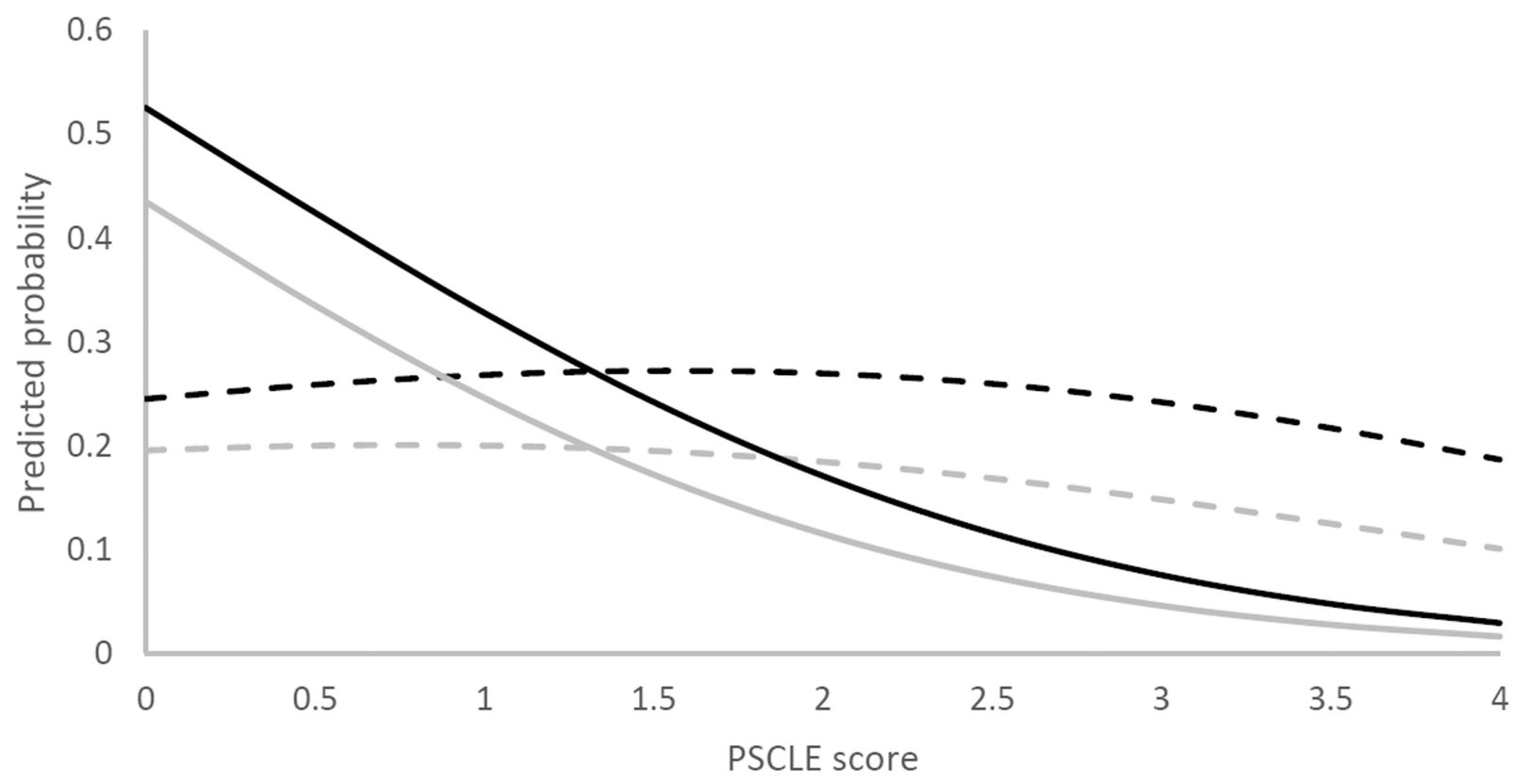

- - -Poor, 2007-8 - - - Poor, 2009+

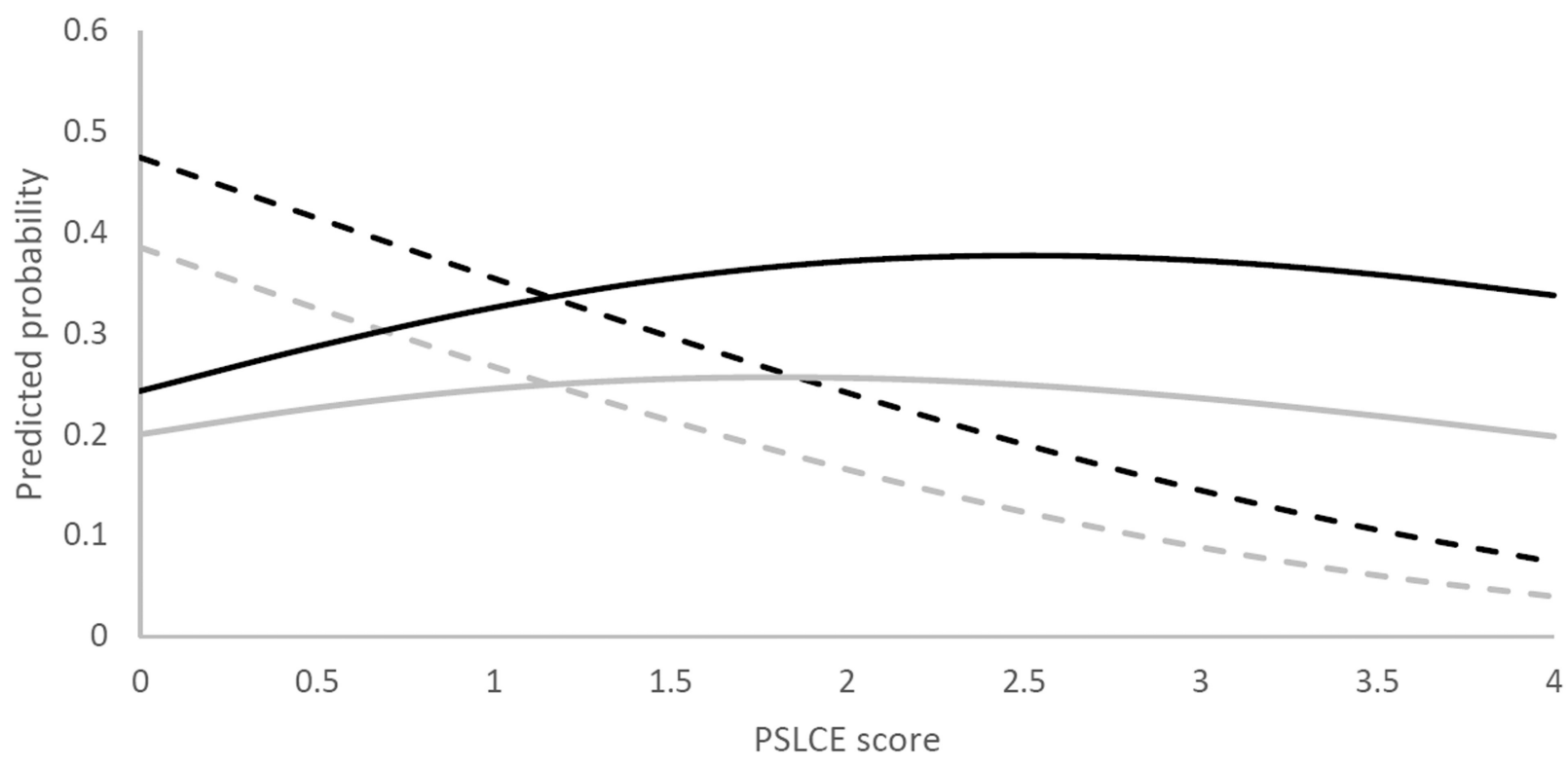

- - - Poor, 2007-8 - - - Poor, 2009+ 


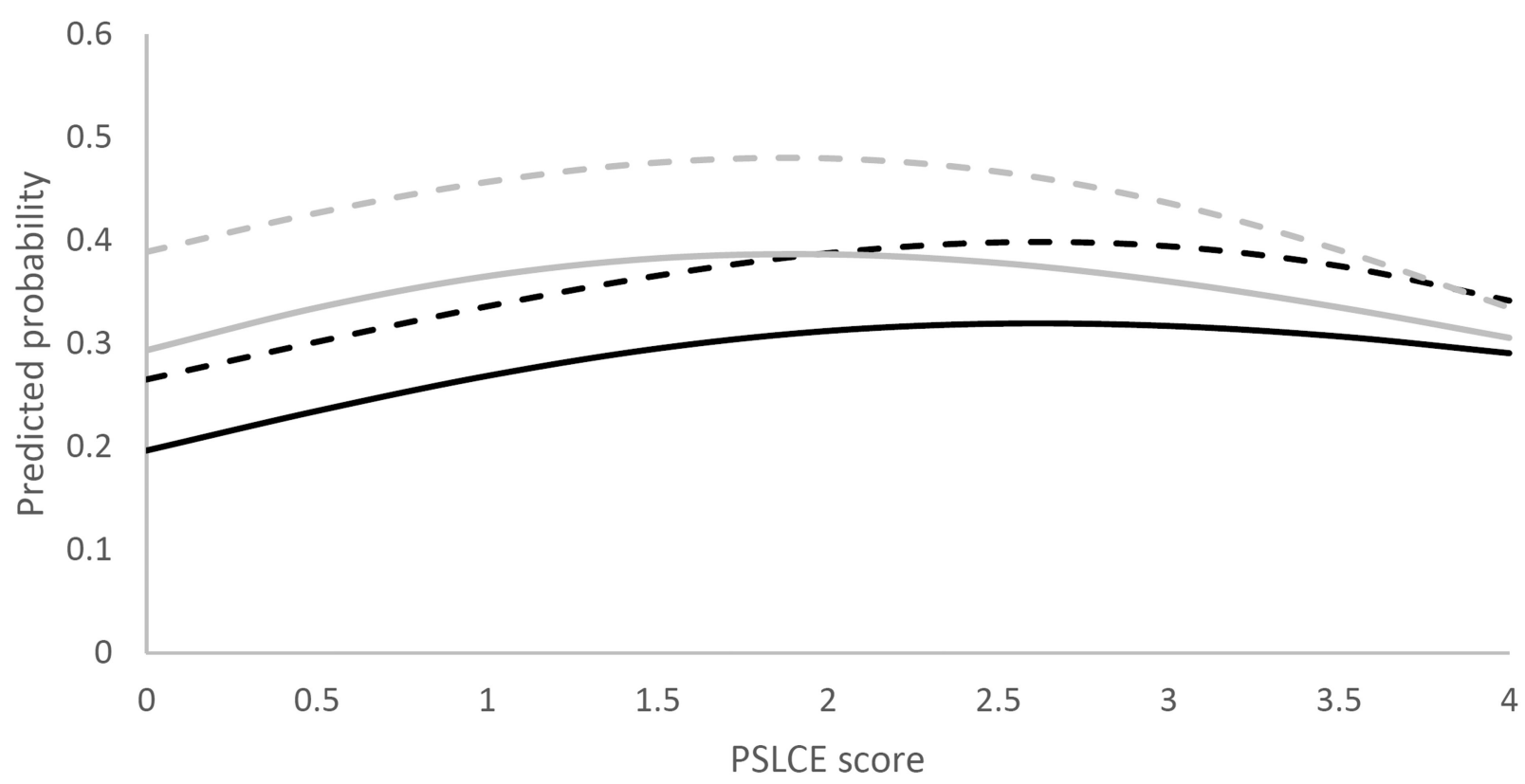

- - - Poor, 2007-8 - - - Poor, 2009+ Non-poor, 2007-8 Non-poor, 2009+

0.6

10.5

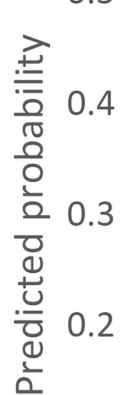

0.1

0

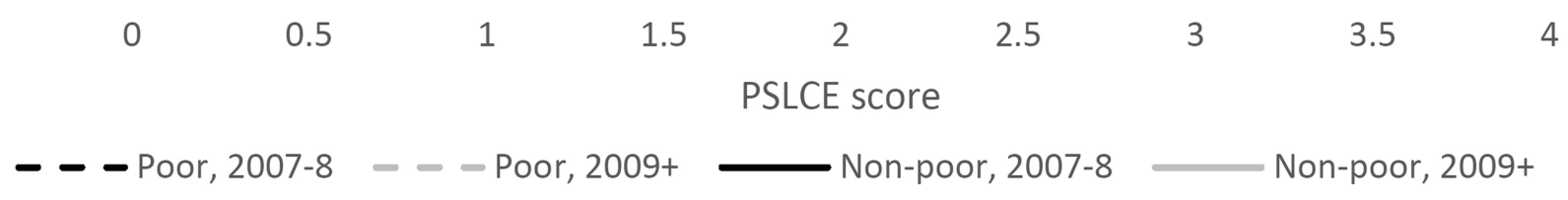

Figure 2.

Soc Forces. Author manuscript; available in PMC 2018 September 01. 
Predicted probability of secondary school enrollment, by household poverty status, year of primary school completion, and PSLCE test score, MSAS 2007-2013.
A. Never enrolled in secondary
B. Private school
C. Second-tier government schools
D. First-tier schools 


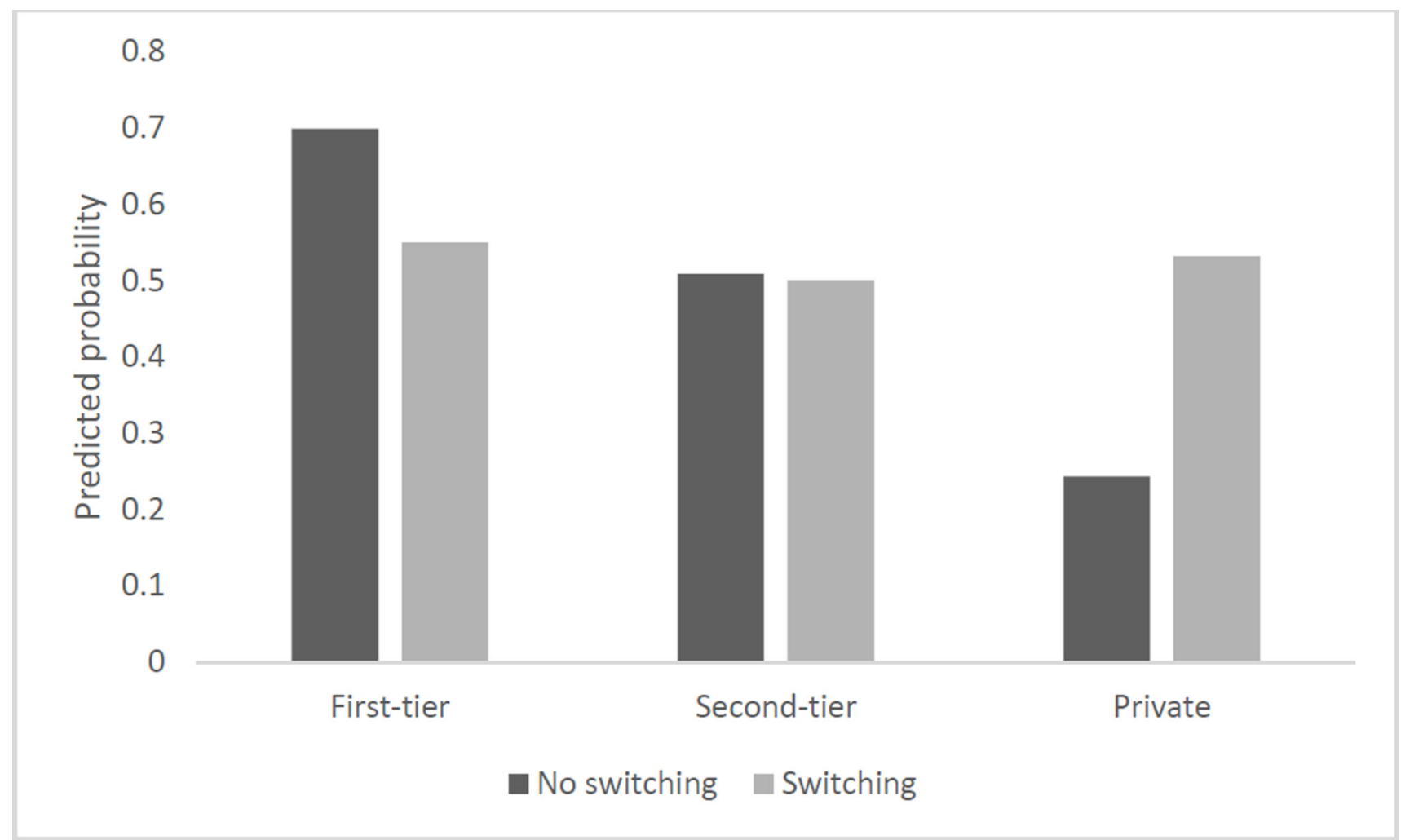

Figure 3.

Predicted probability of enrolling on time in upper secondary, by initial school enrollment type and school switching status, MSAS 2007-2013 
Table 1

Descriptive statistics, analytic samples, MSAS 2007-2013

\begin{tabular}{|c|c|c|c|c|}
\hline & Total & Poor & Non-Poor & \\
\hline Transition to secondary school & & & & $* * *$ \\
\hline Never enrolled & 19.45 & 22.92 & 14.19 & \\
\hline First-tier & 15.6 & 12.76 & 19.93 & \\
\hline Second-tier & 38.67 & 41.11 & 34.99 & \\
\hline Private & 26.27 & 23.23 & 30.89 & \\
\hline Enrolled on time in upper secondary ${ }^{a}$ & 52.89 & 51.32 & 55.09 & \\
\hline Mother attended school & & & & $* * *$ \\
\hline No & 37.44 & 44.51 & 26.71 & \\
\hline Yes & 58.13 & 50.70 & 69.43 & \\
\hline Missing/DK & 4.42 & 4.79 & 3.86 & \\
\hline PSLCE test score, mean (s.d.) & $1.94(0.55)$ & $1.92(0.55)$ & $1.97(0.55)$ & \\
\hline Female & 36.22 & 35.60 & 37.17 & \\
\hline Ethnic group & & & & * \\
\hline Yao & 36.47 & 34.36 & 39.67 & \\
\hline Chewa & 21.59 & 20.62 & 23.07 & \\
\hline Lomwe & 26.93 & 30.98 & 20.77 & \\
\hline Other ethnicity & 15.01 & 14.03 & 16.49 & \\
\hline Age at primary completion, mean (s.d.) & $16.53(1.39)$ & $16.52(1.36)$ & $16.55(1.45)$ & \\
\hline Repeated standard 8 & 16.71 & 16.40 & 17.18 & \\
\hline \multicolumn{5}{|l|}{ District } \\
\hline Balaka & 41.34 & 43.99 & 37.32 & \\
\hline Machinga & 58.66 & 56.01 & 62.68 & \\
\hline Parents' marital status & & & & **** \\
\hline Married to each other & 48.97 & 43.26 & 57.66 & \\
\hline At least one parent died & 13.52 & 14.41 & 12.17 & \\
\hline Divorced & 37.51 & 42.34 & 30.17 & \\
\hline Completed primary in 2009 or later & 37.02 & 32.79 & 43.44 & * \\
\hline Ever switched schools ${ }^{a}$ & 36.33 & 33.84 & 39.83 & \\
\hline $\mathrm{N}$ & 1,069 & 657 & 412 & \\
\hline
\end{tabular}

Note: distributions adjusted for sampling weights and clusters.

$$
\text { p }<0.05
$$$$
\text { * } \mathrm{p}<0.01
$$$$
\text { *** } \mathrm{p}<0.001
$$

${ }^{a}$ These two variables are restricted to respondents who entered secondary school (N=729) 


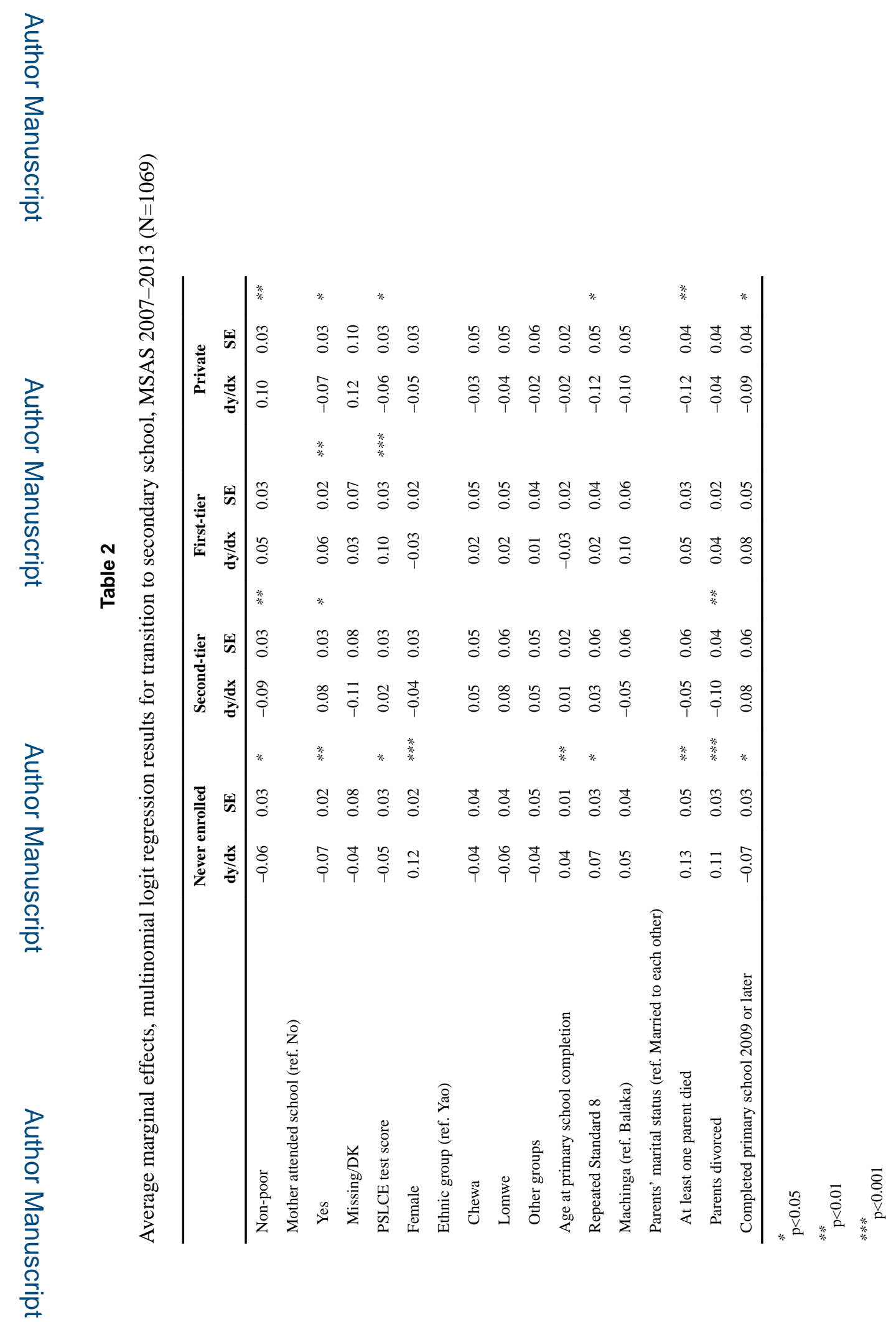

Soc Forces. Author manuscript; available in PMC 2018 September 01. 


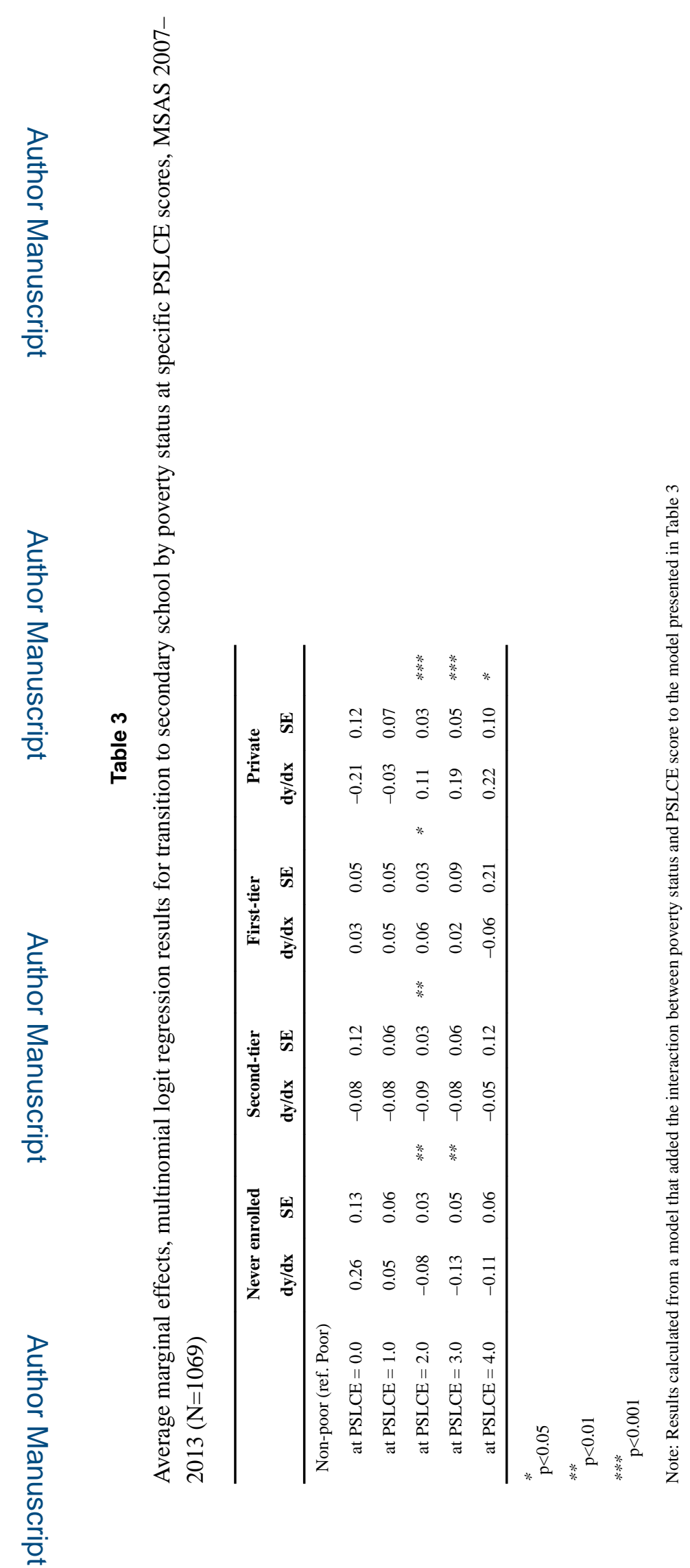

Soc Forces. Author manuscript; available in PMC 2018 September 01. 


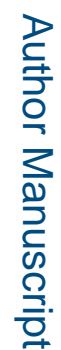

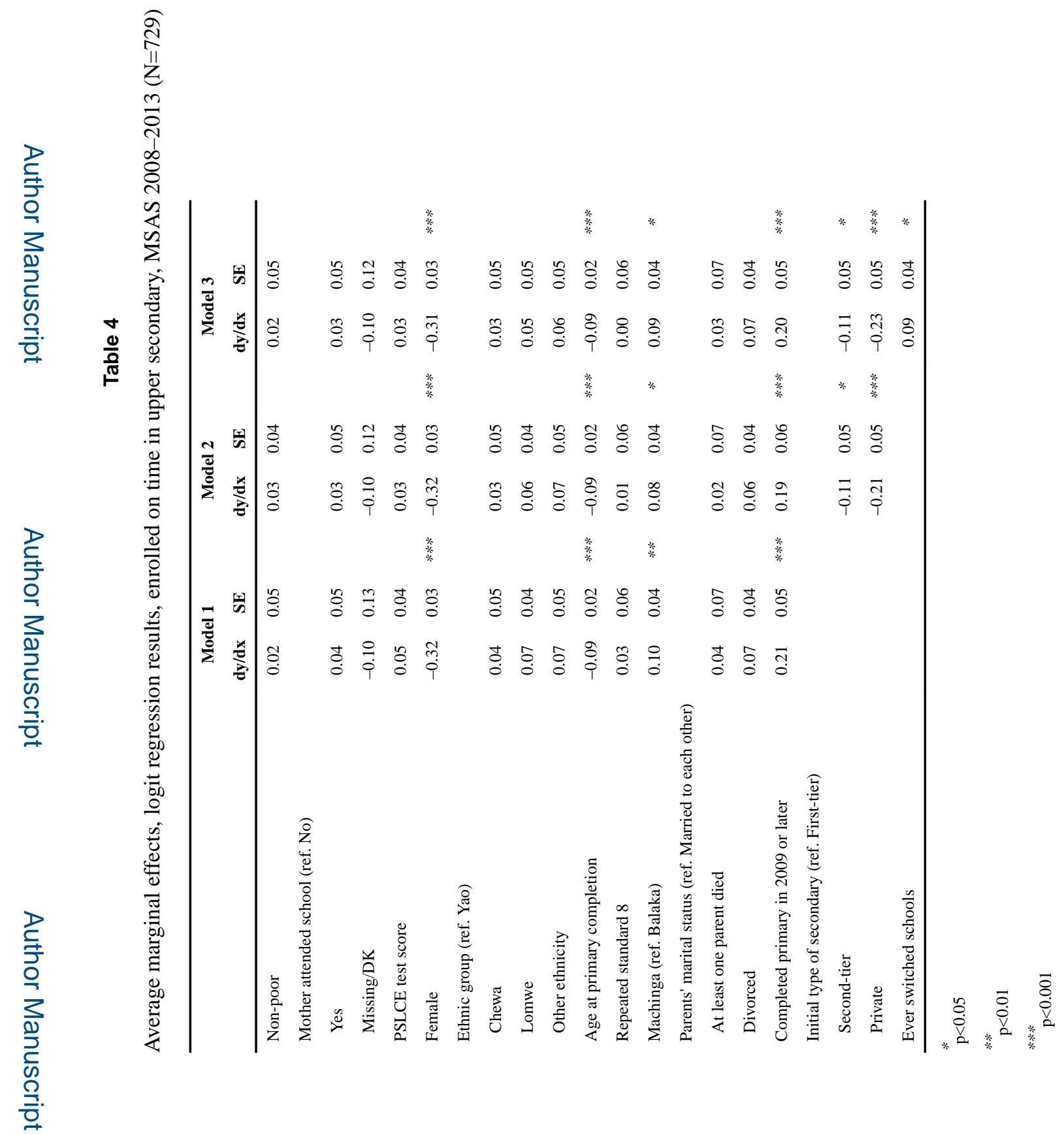

Soc Forces. Author manuscript; available in PMC 2018 September 01. 